\title{
AN AUTOETHNOGRAPHIC ACCOUNT OF TWO INDONESIAN ACADEMIC RETURNEES EXPERIENCED OF REVERSE CULTURE SHOCK
}

\author{
Irfan Rifai ${ }^{1}$, Mukrim Tamrin ${ }^{2}$ \\ ${ }^{1}$ University PGRI Adi Buana, Surabaya \\ ${ }^{2}$ University Tadulako \\ Irifai_irfan@yahoo.com \\ ${ }^{2}$ mukrim.tamrin@gmail.com
}

\begin{abstract}
In this article, we use a duoethnography approach to reflect on our emotional experiences of reintegrating in academic community in two different universities. We start to explore our experience of dialoguing our knowledge, skills and global perspectives in teaching and supervising students in undergraduate thesis writing, demonstrating how we as junior lecturers often making confrontations with the 'conventional' and 'traditional' sounded educational system which have been deep rooted within the Department. In this sense, there has been a conflictual emotion which we should address, utilizing our new knowledge or returning back to the existing norms. Whilst exploring our experiences of dealing with conflictual emotional beliefs, we also examine issue such as identity construction as being an academic returnee responding to the confrontation in academic environment. This study results may resonate the concrete condition of academic returnees reintegrating to their academic milieu in other part of the countries.
\end{abstract}

\section{Keywords: duoauthoethnography, Indonesian academic returnee, and reverse culture shock}

\section{Introduction}

Autoethnography has been widely used as a method in many disciplines to reflect on someone' experience and perspectives from the lens of the authors themselves. In education, Johnson (2020), for example, uses autoethnography to explore his experience of teaching religion at a private and religious high school in the US, specifically his experience of teaching before and after his student's death due to a certain disease (meningitis). In addition, Huber (2020), also uses critical autoethnography to investigate individual and structural failures in online learning from his own perspective as an actor who implements the current method of teaching - online learnin, whilst Hendrix (2020), reflects on her experience of witnessing systematic failures of creating healthier classroom environment in one of the college in the US.

In the area of English language education, Jee (2016) for example, uses authoethnography as her research method to critically views the biased concept of Native and Non-Native Speakers in English language teaching in Korea. How she illustrates her own personal stories to argue that the concept of world Englishes can be a starting point to contend the biased concept of native over non-native. In addition, $\mathrm{Su}$ (2019) also utilizes autoethnography method to propose some suggestions for improvement and development of English language teaching in China from her own perspectives being a learner and a teacher of English subsequently for more than 25 years.

We conducted an autoethnography more specifically duoethnography method to examine our journey of returning back to our educational community from our overseas education. In this paper, we report on our experience of reverse culture shock in educational environment with particular attention given to our experience of teaching a module research method in language teaching and our experience of getting 
involved in academic activities including supervising undergraduate student writing skripsi (undergraduate thesis).

\section{Method}

This study adopts duoethnographies as a research method. Duoethnographies as has been defined by Norris (2017:2) is 'the study how two or more individuals give similar and different meanings to a common phenomenon'. Moreover, Paltridge (2014: 100) asserts that duoethnographies shared similarities to autoethnographies in the sense that it 'draws together features of autobiography and ethnography'. In a more specific, this study uses a combination of two autoethnographies centering on academic reverse culture shock particularly in regard to teaching and supervising students in the area of English language teaching. Through duoethnographies, it enables to examine ourselves (researchers) as research participants and examines our narratives as source and data. Norris (2017), then illustrates that duoethnographies are dialogic in nature in that it provides spaces for two researchers to juxtapose, challenge, and possibly complement their view-points to explore the similar or different meanings of a particular phenomenon.

The two participants as well as the authors, Irfan ( $1^{\text {st }}$ author) and Mukrim ( $2^{\text {nd }}$ author) narrate their lived experiences of academic reverse culture shock during their returning home from overseas study, pursuing $\mathrm{PhD}$ in education in the UK university. Irfan's narrative is mostly derived from his retrospective experience during 2017 to 2019 teaching the module of research method in English language and language teaching and supervising students of English education Department in a private university in Surabaya, while Mukrim's story are highly informed by his experiences teaching and getting involved in academic activities upon returning him to the university in 2019 to 2020. Different from the $1^{\text {st }}$ author place of teaching, the $2^{\text {nd }}$ author is working in a state university in Palu.

In regard to data analysis, this study follows the analysis of duoethnography conducted by Rose \& Montakantiwong (2018) in which the data went through several steps before narratives presentation. The first step was that we wrote our own personal narrative and sent it to each other for perusal. During this perusal, we made comments on our stories followed by asking questions and possibly challenged the narratives of other. Afterwards, reflections and interpretations are made and followed by thematic presentations. We present our autoethnographies as extracts which is similar to thematic analysis presentations.

\section{Result and Discussion}

There are at least two themes and its subthemes which emerged during our narratives analysis. The first theme is around the conflictual emotions about methodology and methods which should be learned and adopted by the students during the course Research Method in English Language and Language Teaching. These conflictual emotions are presented in sub-themes which centered on the dichotomy between two research paradigms, quantitative and qualitative and the research topics which should be considered and selected as their undergraduate thesis' (skripsi) topic. The second theme is about the practical issues in writing the thesis itself which significantly leads to authors' dilemma. This theme is specified into three sub-themes including writing introduction and presenting findings.

\section{Conflictual emotions around introducing the 'current' methodology and methods}

This first theme presented in this study revolves around the most salient events in the classroom we experienced upon returning our overseas education. These classroom events are closely related to our principal task, teaching, as a lecturer in higher education. We are assigned to teach module research methodology and during this teaching module, we found some conflictual emotions regarding the strong and undisputable paradigm dichotomy between quantitative and qualitative as will presented in the following.

\section{Undisputable research paradigm dichotomy}

The following narrative's extract is a representation of our emotion when introducing the qualitative research paradigm in EL and ELT. 
Irfan's story: I was really amazed with the request from the head of the department to teach the module research methodology in EL and ELT. Teaching this module had been my dream before I returned home, dreaming that the intensive trainings and knowledge construction during my $\mathrm{PhD}$ journey will benefits students to the state of art of research methods in English language teaching and learning. I was quite confident that the students and colleagues would welcome me along with the 'new' knowledge I would like to share, opening up a space to the more dynamic and interactive dialogue of the current research methods in EL and ELT. I remembered when I proposed my $\mathrm{PhD}$ proposal to several potential supervisors in the UK and Australian universities, the result was quite relieving, almost all supervisors welcome me to study under their supervision guide. One thing I should not forget about this successful proposal is that the method I utilized in my $\mathrm{PhD}$ proposal is linear with the current issue in language teaching. Departing from this personal experience, I started to talk and share this lived experience to students and colleagues within the department. As for the beginning, there seems to be euphoria for me, all are welcome and happy. The journey begins to be more complex afterwards. The students are likely unwilling to change their minds, arguing that research methods used in their undergraduate thesis writing should be able to measure the results. In this sense, numbering and statistical analysis should ideally be used and my explanations about the nature of qualitative paradigm are unable to be discerned by the students. There seems to be ideological socialization about the method used in thesis writing which passing down from generation to generation. Responding to this situation, I seek for further information and start to check the thesis collection available in the library. What surprising me is that huge number of thesis titles are almost similar, using the typical words such as improving, increasing, the effect and the influence of something to a certain thing. I eventually become more aware that this

\footnotetext{
${ }^{1}$ I finally found that this type of research design is not appropriate for S1 students, as suggested by Prof. Handoyo Puji Widowo, when attending his workshops several
}

ideology is deep rooted within the department.

\section{Mukrim's story:}

In July 2019, I was back in service as a teaching staff in my department of English Language Education. As a new fresh graduate from a University in UK, I was excited to show case my new knowledge and skill gained from my journey as a $\mathrm{PhD}$ student, particularly research knowledge. I was happy when appointed by the coordinator of my Department to supervise some final year students for their skripsi projects, as a part of the requirements to complete study. I was also appointed to be a reviewer in the proposal and defense seminar of some students' projects. However, to my surprise there had not any significant change of students' research design adopted in the study.

Back to 2019, it was the first time I attempted to challenge the status-quo, as I elaborated above. However, I did it eloquently by proposing my idea to one of the senior lecturers, who was in panel with me, when reviewing her supervised-student. I was confident to put forward my idea that we needed to review the policy of the students' final project, emphasizing the adoption of experimental research ${ }^{1}$ without giving them more alternative research designs that might be appropriate for them and suit with their interest and context. Secondly, I argue to her that this fossilized practice would create more plagiarism practice among students, because around hundreds of manuscripts had been produced using similar research design and presented in a similar fashion, encouraging students to copy and paste previous projects. Moreover, no attempt was done to use plagiarism checker, e.g. Turnitin, for students' final project. My argument was backed up by her, and suggested to bring this idea into Department's upcoming meeting, and I was relieved. Although, this idea finally never be realized in the Department level meetings.

times, from October-November 2020. He then labelled it as one of the colonial design, that is widely used by students in English Department elsewhere. 
Changing the established practices for 'a new comer' like us is almost quite impossible. There have generally been conflicts and few new comers are unwilling to take further actions. In this sense, power relations are clearly enacted (Hamilton \& Sharma, 1996) and we as junior lecturers do not have position to challenge the dominant. We come to realize that we are meaningless. We can sense that we do not have power to at least voice our thoughts, although we are quite confidence that through-out the $\mathrm{PhD}$ journey, our thoughts have been challenged and shaped by overseas education. With this is mind, we do not see that our knowledge is valuable and significance for educational transformation in our home university. The existing and perpetuating local culture contributes much to this condition. As has been shown by MA \& PAN (2015) that Chinese returnee find themselves on pressure due to different academic culture. Whilst in western universities academic promotion is based likely on 'what you know', in the Chinese universities are in contrast about 'who you know'. In regard to our powerless to break the fire wall in our university, the strong local culture which position seniors in higher hierarchical system makes it possible for us to change the local culture.

Introducing updated research topics to students and colleagues is not always positively responded.

Relevance to our previous extracts, this subsection presents our further emotional journey particularly in connection to introducing updated research topics to students and colleagues and how this effort has been responded by the students and colleagues resulting our positive and negative emotions.

Irfan's story: Bringing knowledge about the current debate topics in EL \& ELT is not always responded positively. I remembered when I provided students with the current issues in ELT, their thesis' supervisors do not always response positively. When I selected a student with the topic 'motivation in English language learning', for example, her supervisor contends that motivation and its related topics are under the study of psychology and not within English department. I was just surprised by this statement, as I know that research about motivation has been pervasively conducted in ELT and articles about it can easily be accessed in reputable journals. Another example of different perception of research topics within the areas of ELT is English Medium Instruction (EMI). When one student coming to me, asked about EMI, I answered that this topic is one of the popular topics recently. However, I once again need to re-think about what topics actually belongs to ELT, as the topic about EMI is perceived by her supervisor is not quite relevant with topics in ELT. The student told me that EMI belongs to educational management not in English language education. Puzzling with these different perceptions, I calmly confronted to other colleagues that interdisciplinary is emerging in the recent research, explaining that we, lecturers, need to be more open with the dynamic movements. The results, however, is not quite satisfying. They resist that the topics in ELT should be centered around teaching language skills. This paradigm really gets me shocked. Should I follow this circulated discourse about topics in ELT or should I confront them by providing logical reasons and evidences?

\section{Mukrim's story:}

As I mentioned earlier at the paragraph. I was scheduled to teach a "Research in ELT" module. I found that the syllabus perpetuated adopted the positivist paradigm, although give little portion for case study research. Attempting to address the gap, I intentionally introduce some non-experimental research in my two taught classes: e.g. survey research, case study, classroom action research, and how collect data and analyze data using nonstatistical way, as commonly found in existing manuscripts. While I was certain that my course delivery would be different from other lecturers who taught the course in different class, I believed that the students had rights to get new knowledge about research design that might be relevant for them, and give more choices.

My intention was finally paid off, particularly for students who attended my class. Following the outbreak of pandemic Covid 
19, schools are advised to close, and all teaching process were conducted using online platform, leading to the unfeasible adoption of experimental research by students who had programmed it. Students, who written their manuscripts using experimental research, were suggested to shift their research design using non-experimental research during the proposal seminars. As a consequence, those students, who were unfamiliar with nonexperimental research, experienced puzzlements and had no choices to follow what were suggested by their reviewers. However, for some of students who attended my class, this condition would not create little problem as they had been introduced with non-experimental research design; some of them had successfully proposed their manuscripts in proposal seminars.

Dialogue is one of the keys for success in establishing the interaction particularly between lecturer and students. Through two ways dialogue, comprehension and trust can likely be achieved (Ellsworth in Arrington, 2020). In the case of the $1^{\text {st }}$ author, he should create a more space for informal and more relaxed dialogue with his colleagues so that comprehension about the different perspective can be built. Bakhtin 1986 in Ai (2019) reminds us that dialogue in-between academic fields, inter/cross-disciplinary should be promoted in order to learn from others (Marchenkova, 2005) including academic returnee to re-adjust to their own culture.

The issue of re-acculturation to the origin of academic environment is in fact quite common for academic returnee, as has been illustrated in the above extracts. This author's experience is consistent with Park's study (2017) who eloquently illustrates that she experienced reverse culture shock when she sees different values between what she has learned as therapist in the UK and the traditional practices in Korea, causing her resistance and anger. In connection to different educational values, the study which is conducted by Karakas about academic returnee' struggle re-integrating in their home university in Turkey (2020), also shows that $87 \%$ of returnee felt different about their way of thinking compared to those who never lived abroad. Their global knowledge, linguistic and cultural capital are the prevalent factors of their feeling different.

\section{Practical issues in writing an undergraduate thesis}

\section{Writing an introduction}

The different lens about writing introduction in undergraduate thesis can also potentially disrupting authors' emotions. This is not about the contents of introduction, rather; it is about the different concept of deductive in that the introduction should be begin with the general issue then followed by a more specific issue. The term 'general' itself enacts different understandings. We as academic returnee who are getting used to reading and writing in a western style, see that 'general issue' should straightforwardly be connected to the key words found in the thesis title, whilst other lecturers perceive that 'general issue' should be general.

Irfan's story: When hearing my students and colleagues' explanations about the concept general in introduction, I just questioned myself, 'is writing introduction in thesis should be different from writing an introduction in a journal article?'. As my experience writing $\mathrm{PhD}$ thesis, I straightforwardly write an issue which is relevant with my title. For example, when my $\mathrm{PhD}$ thesis title is about school violence, I focus on writing the issue of school violence in my introduction. Moreover, as my intensive reading $\mathrm{PhD}$ theses from the UK universities, the introduction closely relates to the title. Having been read undergraduate theses available in the department's library, I can see the homogeneity of writing an introduction. This introduction as I perceived is too broad and not quite specific. For example, I see the title is about the influence of songs to vocabulary mastery among lower secondary school students, but the opening introduction is mostly about teaching language and language skills. The introduction is mostly occupied with the general issue such as language skills and the definitions and types of songs, tending to neglect the key issues found in the title. This seems to be a general acceptance among students and lecturers within the department, as mostly undergraduate theses follow this typical style when writing an introduction. Recognising this condition, I become 
dilemmatic. Arguing the establishing and firmed style can be frustrating, following the existing style can jeopardise my cognitive and belief. This situation really puts me in dilemma.

\section{Mukrim's story:}

When writing the rationale of doing the research (experimental research) in the introduction section, most students did not review previous articles as a basis of gap for doing the research. Indeed, their rationale was based on practical reasons, for instance to solve the students' learning issue of particular skill that had been previously observed when conducting teaching practicum. This rationale was definitely identical to the classroom action research than that of experimental research. Moreover, in the literature review chapters, although review of previous study was done, it was more descriptive than critically review the previous studies. Moreover, presenting 2 studies only would not suffice to inform the researcher any empirical gaps for their studies.

Framing and comparing different style of academic writing between home university and the western academic tradition indicates that we as academic returnee possessing new competence, skills and worldview to position ourselves different from those who are still maintaining their conventional practices in the home university. This different position is a primary factor that academic returnee struggle to re-integrate to the academic environment. This condition is also illustrated by Song (2016) about the teachers' negative perspective towards the students' returnee who can-not comply with the local norms in English language subject, due different position between students and teachers in term of their English language skills.

\section{Presenting findings in undergraduate thesis writing}

There have been differences between the ways students write in findings' section and the ways we understand about presenting findings. These differences are mostly about the presenting data and data interpretations. As we are familiar with the use of extracts as evidence to support our arguments and interpretations, we found that students' undergraduate thesis presents only their interpretations without necessarily supported by the extracts which generally garnered from data collection methods.

Irfan's story: Another different conception about writing undergraduate thesis is about presenting the findings. I read the students' thesis focusing on finding section and found that the data presented are often still raw. Another surprising issue about presenting the findings is that mostly the students did not include extracts as evidence to support their interpretations. The interpretations let alone the writers, sounding like presenting their own story. Moreover, as see in discussion section, there is no really discussion, illustrating the dialogue between the current findings and the previous research findings. When I asked colleagues, the answers are not quite convincing, moving around the definitions without necessarily presenting the practical guidelines. I became frustrated afterwards. If I supervise my students writing undergraduate thesis, I will strongly ask them to include extracts or any evidence which can support their interpretations.

\section{Mukrim' story:}

Most students were poor in writing up the discussion of their findings. It was constructed descriptively presenting statistical results without attempting to connect with references, reviewed in the literature review chapter. This typical work seems imitating from the previous skripsi which had been practiced by their seniors, compounding with lack of attention given by the reviewers to this issue and poor students' research knowledge and academic writing. It was really sad and impacting on my thoughts. However, this issue has prompted the discussion among the manager and lecturers to introduce a new course of academic writing for publication. This initiative is also expected to promote students and lecturers could create a more sounded academic writing that can be published in reputable national and international journals. Given this, the review of existing syllabus of Research in ELT module has also been planned in the upcoming Departments meeting, before the subsequent semester.

The imitating practice in skripsi writing as has been pointed by the $2^{\text {nd }}$ author can be 
linked to the concept of collectivism and dependence and Indonesia can be perceived to be a collectivist country. In this regard, the students show their collectivist culture in that they compliant to group practice over their own and this practice has been internalized as the truism. In relation to the experience of two authors experiencing culture shock, Park (2017) contends that the greater the cultural differences, the more difficult to reacculturate. This what happen with us, we find really hard to re-acculturate our own into the academic collectivism system. This condition also occurs with a Chinese academic returnee who present their mixture feeling about re-integrating to his homeland's university (Ai \& Wang, 2017). Through their autoethnography method, they illustrate how they are quite distress in re-adapting to their homeland's university system and one of the factors contributing their distress is about the different expectations between the returnee and the people around them.

\section{Conclusion}

This paper illustrates our emotional experience of re-integrating ourselves with our home institution via an autoethnography method. This method provides us a space to reflect on our struggle to dialogue our knowledge, skills and global perspective we gained during our overseas study to the local academic culture. This dialogue is one of the ways for us as an academic returnee to reintegrate to our academic environment. However, there have been prominent factors which disrupt our efforts to re-integrate to our academic environment spanning from different educational culture and values, different position, and different system of culture.

\section{References}

Ai, B. \& Wang, L. 2017. Homeland integration: an academic returnee's experiences in Chinese universities. International Journal of Qualitative Methods. 16 - 1-9. DOI: $\underline{10.1177 / 1609406917696741}$

Ai, B. 2019. Pains and gains of working in Chinese universities: an academic returnee's journey. Higher Education
Research \& Development. DOI: 10.1080/07294360.2019.1590320

Arrington, M., I. 2020. When teaching failed in the interracial communication course: on the need to teach dialogue and the need to teach dialogically. Communication Education. 69:4, 431440 , DOI: 10.1080/03634523.2020.1804068

Hamilton, T. \& Sharma, S. 1996. Power, power relations, and oppression: $a$ perspective for balancing the power relations. Peace Research. 28,1, 2141.

Hendrix, K, G. 2020. When teaching fails due to third-party interference: a blackgirl Warrior's story. Communication Education. 69:4, 414-422, DOI: $\underline{10.1080 / 03634523.2020 .1804067}$

Huber, A., A. 2020. Failing at the help desk: performing online teacher. Communication Education. 69:4, 464479, 10.1080/03634523.2020.1803379

Jee, Y. 2016. Critical perspectives of world Englishes on EFL teachers' identity and employment in Korea: an autoethnography. Multicultural Education Review. 8:4, 240-252

Johnson, W. 2020. When a student dies. Communication Education. 69:4, 423430.

DOI:10.1080/03634523.2020.180337 7

Karakas, A. 2020. Disciplining transnationality? the impact of study abroad educational experiences on Turkish returnee scholars' lives, career and identity. Research in Comparative \& International Education. 1-21. DOI: $\underline{10.1177 / 1745499920946223}$

MA, Y \& PAN, S. 2015. Chinese returnee from overseas study: understanding of barin gain and brain circulation in the age of globalization. Fron. Educ. China. 10:2, 306-329. DOI 10.3868/s110-004-015-0019-6

Marchenkova, L. 2005. Language, culture, and self: the Bakhtin-Vigotsky encounter. In J. K. Hall, G. Vitanova, \& L. Marchenkova (Eds.), Dialogue with Bakhtin on second and foreign language learning: new perspectives. Mahwah, NJ: Lawrence Erlbaum 
Journal Sampurasun : Interdisciplinary Studies for Cultural Heritage

Vol. 6, Number 2, December 2020

Associates.

Norris, J. 2017. Duoethnography. InL Given $L M$ (ed.) The SAGE Encyclopedia of Qualitative Research Methods. Thousand Oaks, CA: SAGE Publications, 233-36.

Paltridge, B. 2014. What motives applied linguistics research? AILA Review. 27:1, 98-104.

Park, B. 2017. A Korean art therapist's autoethnography concerning reacculturation to the motherland following training in the UK. International Journal of Art Therapy. DOI:

10.1080/17454832.2017.1296008

Song, J. 2016. (I1) Legitimate language skills and membership: English teachers' perspectives on early (English) study abroad returnee in EFL classrooms. TESOL Journal. 7:1.

Su, C. 2019. Characteristics and limitations of English language teaching in China: autoethnography of a mainland-born English learner and teacher. Changing English; Studies in Culture and Education. DOI: 10.1080/1358684X.2019.1584524 